\title{
Identifying urban features for vulnerable road user safety in Europe
}

\author{
Marina Klanjčića ${ }^{\mathrm{a}}$, Laetitia Gauvin ${ }^{\mathrm{a}}$, Michele Tizzoni ${ }^{\mathrm{a}}$, and Michael Szell*a,b \\ ${ }^{a}$ ISI Foundation, Via Chisola 5, 10126 Torino, Italy \\ ${ }^{\mathrm{b}}$ Computer Science Department, IT University of Copenhagen, Rued Langgaards Vej 7, 2300 København, Denmark
}

April 14, 2021

\begin{abstract}
One of the targets of the UN Sustainable Development Goals is to substantially reduce the number of global deaths and injuries from road traffic collisions. To this aim, European cities adopted various urban mobility policies, which has led to a heterogeneous number of injuries across Europe. Monitoring the discrepancies in injuries and understanding the most efficient policies are keys to achieve the objectives of Vision Zero, a multi-national road traffic safety project that aims at zero fatalities or serious injuries linked to road traffic. Here, we identify urban features that are determinants of vulnerable road user safety through the analysis of inter-mode collision data across European cities. We first build up a data set of urban road crashes and their participants from 24 cities in 5 European countries, using the widely recommended KSI indicator (killed or seriously injured individuals) as a safety performance metric. Modelling the casualty matrices including road infrastructure characteristics and modal share distribution of the different cities, we observe that cities with the highest rates of walking and cycling modal shares are the safest for the most vulnerable users. Instead, a higher presence of low-speed limited roads seems to only significantly reduce the number of injuries of car occupants. Our results suggest that policies aimed at increasing the modal share of walking and cycling are key to improve road safety for all road users.
\end{abstract}

\section{Introduction}

Road traffic crashes result in yearly 1.3 million deaths and 50 million injuries, and are the world's leading cause of death for children and young adults 5-29 years of age [1]. The World Health Organization quantifies the economic costs of road traffic crashes to $3 \%$ of the global GDP, or 2.3 trillion USD. Because of this pressing societal issue, the UN has declared in 2015 the global sustainability goal to halve the number of global deaths and injuries from road traffic crashes by 2020 [2]. However, traffic deaths and injuries have kept rising worldwide instead of decreasing, and the UN goal has been missed [1.

On a global level, the WHO's explanation for this failure is the heterogeneity of progress: while casualties from road traffic have overall stagnated or decreased in high income countries, they have increased in low and middle income countries. For example, on the one hand, road fatalities have decreased in the EU (although EU-wide targets to significantly lower traffic crashes have been missed [3]). On the other hand, in most African and South-East Asian countries, road fatalities have stagnated or grown exceptionally high [1].

The WHO report also shows that vulnerable road users - pedestrians, cyclists, and motorcyclists - are disproportionally affected. Increased urbanization has therefore made clear that implementing effective urban planning policies at scale is necessary to overcome such failures [4]. In particular, the UN's current sustainability goal 11 to "Make cities inclusive, safe, resilient and sustainable" [2] is a key to decrease road casualties worldwide [5].

In this study, we seek to identify urban features that are determinants of vulnerable road user safety through the analysis of inter-mode collision data across European cities. We first build up a high-quality data set of urban road collisions and collision participants from 24 cities in 5 European countries, using the widely recommended KSI indicator (killed or seriously injured individuals) as a safety performance metric [6]. We then apply machine learning tools on this established data set to identify 1) the biggest danger to vulnerable traffic participants per city, and 2) the most relevant urban features - extracted from OpenStreetMap [7 - that are associated with higher safety for road users. This approach follows a human-centric urban data science $[\underline{8}$ that aims to generate value for citizens by applying data science methods on large-scale urban data sets.

Our work follows in the footsteps of a wide literature of data-driven studies on road safety. Previous studies investigating the determinants of road safety have typically considered a subset of dimensions, including vehicle type, road infrastructure, traffic and control, environmental factors, through the regression analysis of individual

*Corresponding author. Email: misz@itu.dk 


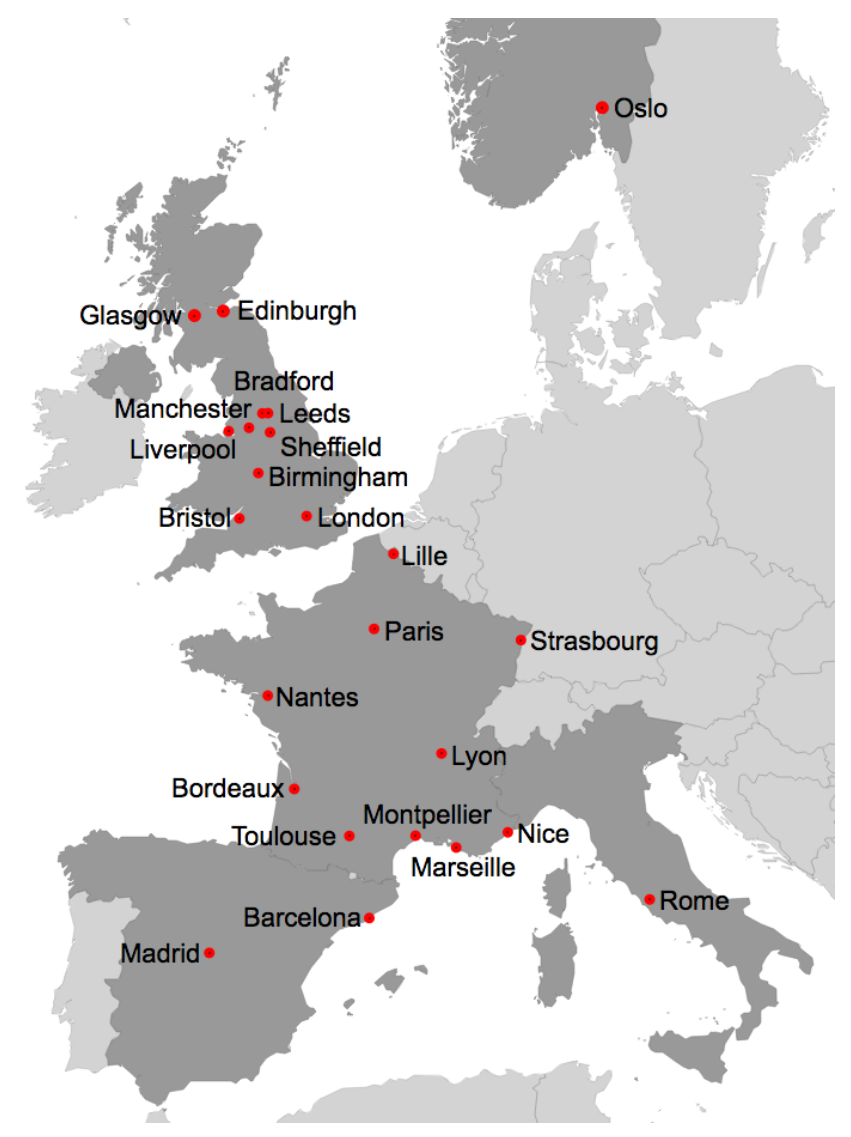

Figure 1: Map of the cities included in the study. We collected, processed, and aligned fine-grained road crash data and urban features data from OpenStreetMap for the 24 European cities shown in the map, in France, Italy, Norway, Spain and the United Kingdom, in the year 2018.

crash data 9, 10, 11, 12. Most of them have a limited geographical coverage, usually focusing on one particular city or region, with some notable exceptions typically on policy questions [13, 14, 15, 16, 17. Also, many of these studies took into account a single transport mode [18, 19] (e.g. cyclists, or pedestrian), yet increasingly on vulnerable road users [20, 21, 22, 23], but usually only limited to the victim participant in the crash [24]. In particular, among vulnerable road users, cyclists have received considerable attention by recent studies. Cycling is one of the most sustainable mobility solutions for short and medium distance trips, but faces considerable risks imposed by motorized vehicles. The risk for injury has been quantified recently in London using a multilevel regression model accounting for exposure, finding that lower speed limits and more cycling routes can be a crucial factor [25]. A more recent study of data from Spain followed a Bayesian network approach to identify the most relevant features for cyclist injury severity, finding higher risk posed by heavy goods vehicles and lower risk from certain route conditions [26]. Other approaches use GIS methods to link objective and subjective risks [27, bicycle trip data of a public bicycle rental system to proxy the bicycle crash exposure [28], crowdsourced bicycle incident reports to characterize patterns of injury [29], spatio-temporal trends [30], and analysis of intersections or bicycle infrastructure [31, 32, 33, 34, 35.

To summarize, the majority of studies on urban road safety focus on crash victims, often from a single mode, and only in specific cities or regions. However, there is a clear lack of research that considers both sides of a crash from all traffic modes to identify inter-mode hazards, together with multiple cities to control for regional peculiarities.

Here we fill this gap by following the three main recommendations of the OECD for developing evidencebased approaches to road safety [36, 37]: 1) to collect and analyze crash data "from a larger set of cities", 2) to investigate "the relationships between urban shape, density, speeds, modal share and road user risk", and 3) to place "an immediate focus [...] on the analysis of casualty matrices to reveal the number of people in each user group who are killed or seriously injured in crashes involving another user group". By doing so, we adopt an ecological study approach that takes into account all traffic modes and casualty matrices across multiple European cities, and that considers the exposure to different population-level urban features as determinants of road safety. 


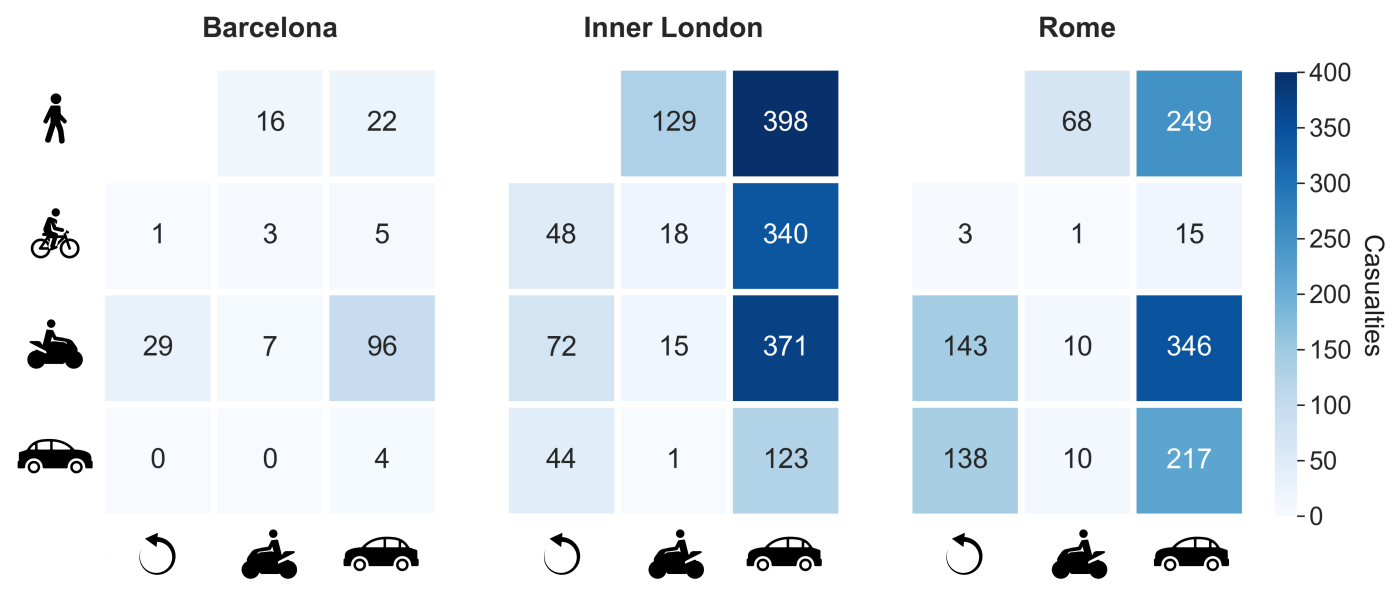

Figure 2: Casualty matrices for Barcelona, Inner London and Rome demonstrate heterogeneity of road traffic risks. The casualty matrix shows the number of killed or seriously injured people in 2018 after a traffic participant on the left collided with one on the bottom. The leftmost column (above the symbol $\circlearrowleft$ ) denotes a crash with only one participant, indicating self-risk. The heterogeneity of posed risks is apparent: Cars are responsible for the majority of road deaths/injuries, while columns for pedestrians and cyclists do not appear because they pose practically no risk to others. Further, these examples also reveal the heterogeneity of risks to specific vulnerable participants through different cities, for example a much higher relative risk to pedestrians in London than in Barcelona. See Fig. S1 for a full picture including more traffic participants and all studied cities.

\section{Results}

\section{Establishing a road casualty data set with inter-mode impacts}

We collected road casualty data from 24 European cities in 5 countries (Spain, Italy, France, UK, and Norway) as shown in Fig. 1 from the year 2018, which was the most recent data available at the time of the study. Of the 24 cities 10 are in France and 10 are in the UK. For more details about the data collection and processing see the Methods section. The data contain records of road crashes in each city, in a line list format, with details about the individuals injured, the severity of the injuries, and the types of vehicles involved. A complete description of the records is reported in the Methods section.

Based on the crash records, we created casualty matrices reporting the number of individuals killed or seriously injured (KSI) caused by the collision of any two pairs of road user types, in each city. Among all road users, we focused in particular on the vulnerable ones, that is pedestrians, cyclists, and powered two-wheelers, apart from cars. As an illustrative example, in Fig. 2, we show the casualty matrices for 3 cities: Barcelona, Inner London and Rome. Casualty matrices for all other cities are shown in the Supplementary Information (Fig. S1). While the highest risk for vulnerable users is expectedly represented by cars in all the cities, the number of KSI varies significantly by user group. For instance, the casualty matrix of Barcelona shows a high level of road safety not only for vulnerable users but for car drivers too, with only 4 KSI reported in car-car collisions in 2018 .

To better compare road safety levels of all cities in our dataset, we normalized the number of KSI, for each type of collision, by population size. Figure 3 shows the number of KSI individuals per 1 Million inhabitants, as a stacked bar chart, where each bar corresponds to a specific type of collision. The chart reveals the high heterogeneity in road safety across the cities under study. On the one hand, we have an extreme case like Sheffield with almost $500 \mathrm{KSI} / \mathrm{M}$, and, at the top of the safety rank, Oslo that is the safest city in our dataset with less than $50 \mathrm{KSI} / \mathrm{M}$ in 2018. The highest KSI rates among the most vulnerable road users, pedestrians and cyclists, were recorded in Inner London (308 KSI/M), Liverpool (198 KSI/M), and Birmingham (181 KSI/M), followed by the rest of the British cities. Instead, the highest KSI rates for powered two-wheelers were reported in Marseille, Rome and Nice. British cities were also the least safe for car drivers, with Sheffield leading the rank by KSI rates in car-car crashes, immediately followed by Birmingham. French cities show medium to low rates of KSI individuals across all types of collisions, with the exception of Marseille that ranks as the second least safe city in our dataset $(387 \mathrm{KSI} / \mathrm{M})$. National capitals also show very different levels of road safety, as Rome and Inner London display almost $400 \mathrm{KSI}$ M. while Paris ranked as the 5th safest city of our dataset, with $132 \mathrm{KSI} / \mathrm{M}$. 


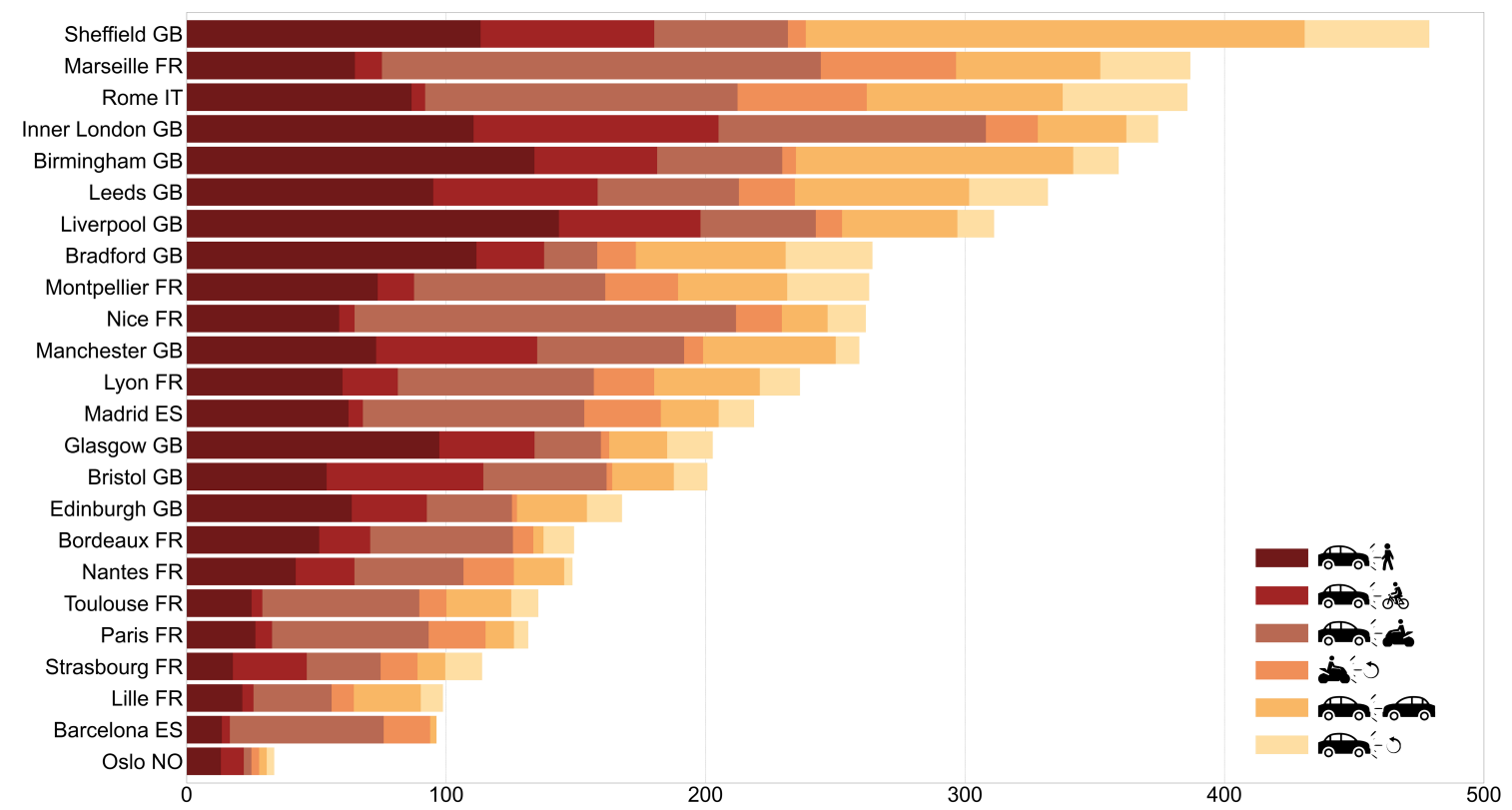

Figure 3: Killed or seriously injured (KSI) individuals per 1 million inhabitants are heterogeneous between different cities and road participant pairs. The figure reports very different levels of road safety in terms of killed or seriously injured (KSI) individuals per 1 million inhabitants in 2018. Sheffield (GB) leads with almost 500 KSI, whereas Oslo (NO) has close to zero KSI. French cities mostly have lower KSI rates, in contrast to most of the British cities which show high KSI rates often double the amounts of French cities. The most vulnerable traffic participants, pedestrians and cyclists, are highlighted in maroon and red, respectively. Their KSI rates are highest in Inner London (GB), Liverpool (GB), and Birmingham (GB).

\section{Urban features as determinants of road safety}

To explain the observed heterogeneities in road safety across European cities, and in particular for vulnerable users, we examined the relationship between a number of urban features and the inter-mode KSI rates shown in Fig. 3. We collected data regarding 7 different urban features in the 24 cities using OpenStreetMap (OSM) and from the European Platform on Mobility Management (EPOMM). A complete description of the data collection process is reported in the Methods section. The features considered in our study are: population density, the ratio of total cycling area to total driving area, the ratio of total low-speed limited area to total driving area, modal shares for walking, cycling, public transport, and motor vehicles. Fig. S2 and Fig. S3 provide an overview of the urban features and the modal shares, respectively, in the 24 cities. All cities displayed a high variability in the urban features and modal shares, also within the same country. Population density ranges from $1,417 \mathrm{pop} / \mathrm{km}^{2}$ in Oslo to $20,000 \mathrm{pop} / \mathrm{km}^{2}$ in Paris. The cycling area share of the total streets is only $3 \%$ in Rome but is more than 30\% in Strasbourg and Nantes. The speed limited area share varies over more than an order of magnitude across cities, from $2 \%$ in Bradford to $87 \%$ in Inner London. Modal shares are also very different across the 24 cities. Paris ranks first by walking share (47\%) and last by motor vehicle usage (17\%). Cycling modal share is generally low, below $4 \%$ in all cities, with exception of Bristol (14\%), Strasbourg (8\%) and Nantes (5\%). Public transport leads the modal share of Barcelona (39\%) while it is less common in French cities, like Montpellier (8\%) and Bordeaux (9\%).

For all cities, we examined the relationship between the above urban features and the inter-mode KSI rates by a multiple linear regression with variable selection through the Lasso procedure, as described in the Methods. Each regression coefficient $\beta$ and its associated $95 \%$ confidence interval (CI) quantify the relations of each variable with the inter-mode KSI casualty rates. The main results of the model are summarized by Fig. 4 which shows the association between each urban feature (rows) and the inter-mode KSI rate (columns) of collisions that involved at least one car. Each entry of the matrix reports the regression coefficient associated with a given feature when predicting the KSI rates of a given collision type. Negative values indicate a reduction of KSI rates and statistically significant values at $p<0.05$ are highlighted by a solid box.

First, let us focus on modal share, i.e. the bottom three rows in Fig. 4 In general, larger shares of walking and cycling were most frequently selected by the model to predict a reduction in all type of KSI rates. In particular, the share of walking was significantly associated with the inter-mode KSI casualty rates of 3 collision types. Cities with a higher walking share showed to have lower KSI rates for pedestrians $(\beta=-0.48,95 \%$ CI $[-0.81,-0.15])$, cyclists $(\beta=-0.57,[-0.97,-0.17])$ and car/taxi occupants $(\beta=-0.46,[-0.90,-0.03])$ when injured in a collision with a car or taxi. Walking share was also negatively associated with single-vehicle car crashes, even though it did not show to be statistically significant. A larger cycling share was also associated - although 


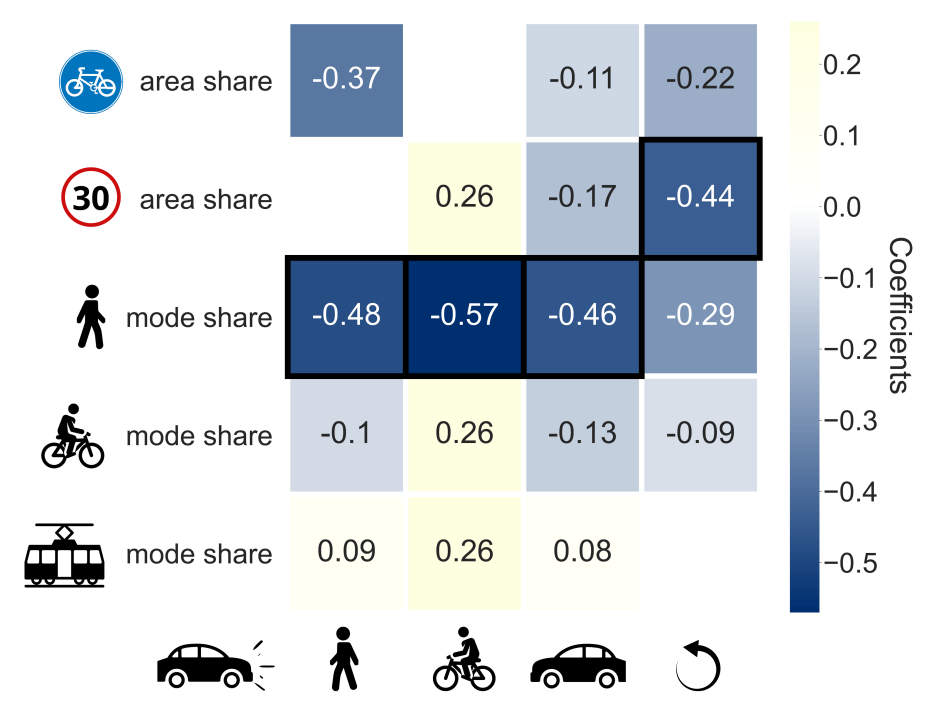

Figure 4: Walking modal share is a significant predictor for inter-mode KSI casualties. The figure reports regression coefficients for inter-mode casualties per capita and urban features. Each column represents a participant type killed or seriously injured by car. Each row represents an urban feature selected by the regression model (the blue bicycle icon denotes the area share of protected cycling paths, the red circled icon denotes the share of areas with speed limits of at most $30 \mathrm{~km} / \mathrm{h}$ or $20 \mathrm{mi} / \mathrm{h}$, the last three rows denote modal share of walking, cycling, and public transport). Empty cells mark the features that were discarded by the model. Black solid boxes denote the statistically significant variables at $p<0.05$.

not significantly - with lower KSI rates of pedestrians, and car occupants in collisions with cars.

Next, let us examine the features related to infrastructure, i.e. the top two rows in Fig. 4 . The model showed that cities with a higher proportion of low speed limited streets with respect to the total driving area (second row in Fig. 44), are characterized by lower KSI rates for both single-vehicle car crashes $(\beta=-0.44$, [-0.79, -0.09], significant) and car-car crashes (not significant). A positive association without statistical significance was observed between low-speed limited area share and cyclists injured by a car/taxi. With pedestrian KSI rates the proportion of low-speed limited streets had no detectable relation. When it comes to the proportion of protected cycling paths (first row in Fig. 4), we found the following not significant effects: a larger proportion was associated to lower inter-mode KSI casualty rates for pedestrians, car/taxi occupants, and single-vehicle car/taxi occupants. The largest effect between these three on the KSI rates was found for pedestrians $(\beta=$ $-0.37)$.

Finally, our model selected the public transport share as positively associated with KSI rates for pedestrians, cyclists and car/taxi occupants, although not statistically significantly.

\section{Evaluating model performance on inter-mode KSI rates}

We examined the quality of our model's predictions, for the KSI rates of all collision types that involved at least one car. Figure 5 shows the results of the regression as predicted vs. reported KSI rates, for collisions between cars and the vulnerable road users of pedestrians and cyclists. In both cases, as shown in the maps, road safety is lowest in British cities, especially for cyclists, when compared to the rest of our sample. Overall, the model reached a good performance in predicting the KSI rates of pedestrians hit by a car or taxi (adjusted $R^{2}=0.527$ ). The model's performance was lower (adjusted $R^{2}=0.349$ ) for the KSI of cyclists, as indicated by some outliers in the scatterplot. In particular, the KSI rate of cyclists in Inner London was more than double than predicted by the model, based on the selected features. On the other hand, the model predicted relatively higher KSI rates for cyclists than those reported in Rome, Barcelona and Oslo.

Model results for KSI rates of car occupants are shown in Fig. 6. The model's performance was better for collisions involving one car and no other vehicles adjusted $R^{2}=0.471$ as KSI rates did not differ much between predicted and reported (Fig. 6D). The performance of the model was lower in the case of car-car collisions adjusted $R^{2}=0.302$, mostly due to a single large outlier - Sheffield - where the reported KSI rate was 192 $\mathrm{KSI} / \mathrm{M}$ but the model predicted a value below $100 \mathrm{KSI} / \mathrm{M}$. On the other hand, the model was better able to predict KSI rates of car occupants in countries characterized by mid to low KSI rates $(<50)$, like France and Spain.

We also performed a multilinear regression to predict the KSI rates of power two wheelers in collisions involving one car or one single vehicle. In this case, the Lasso regression did not select any of the features included in the model, indicating a lack of predictive power (see Fig. S4). 

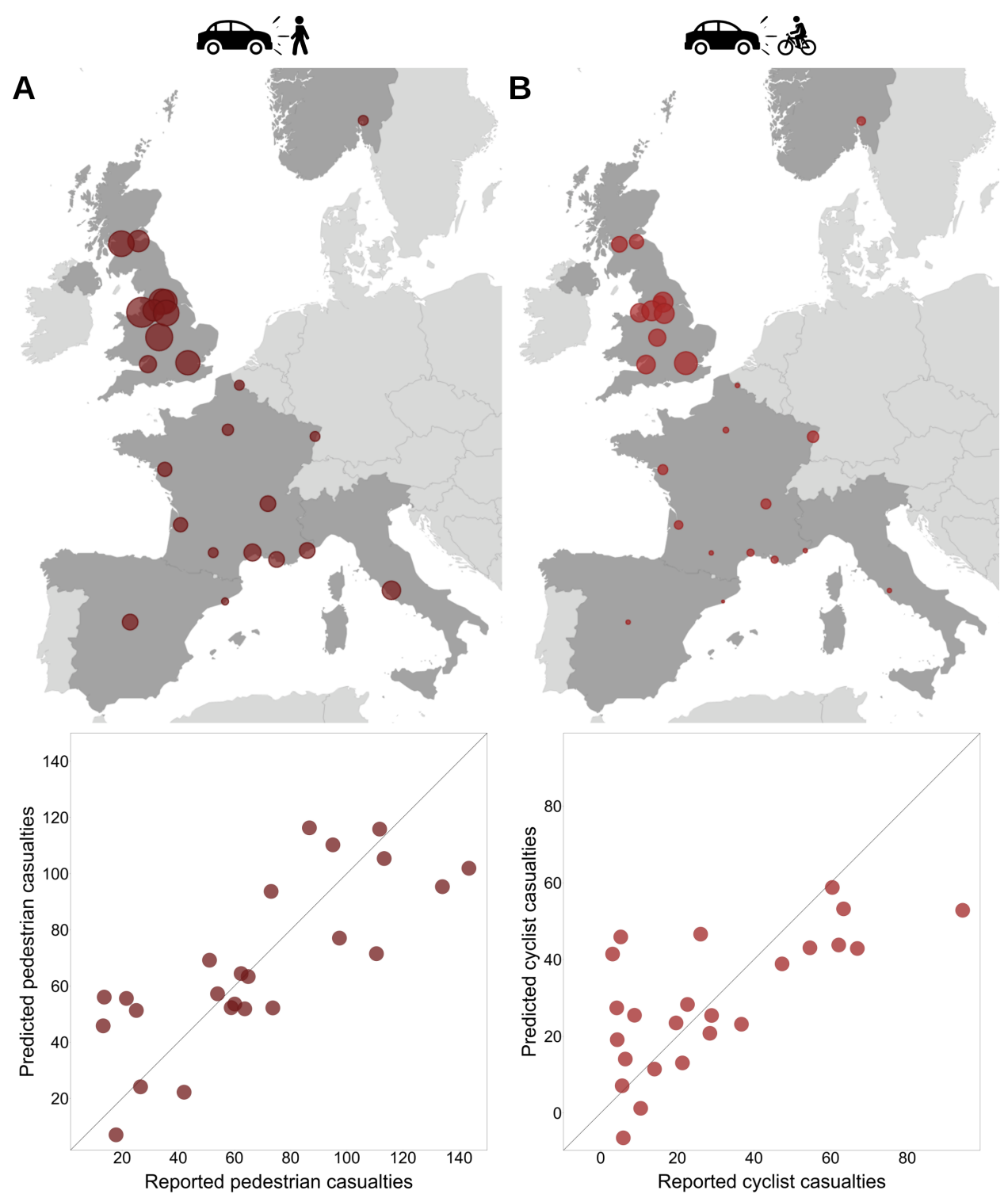

Figure 5: Collisions involving vulnerable road users: maps of the collisions and performance of the models. Maps are showing the reported numbers of vulnerable road users killed or seriously injured by a car or taxi, normalized by population. Scatter plots show the corresponding prediction results. Panel A refers to pedestrians, while panel B refers to cyclists. Colours correspond to those used in the legend of Fig. 3 Of the 24 cities under study, the 10 cities with the lowest vulnerable road users' safety are British cities. Prediction results showed adjusted $R^{2}=0.527$ in panel A and adjusted $R^{2}=0.349$ in panel $\mathrm{B}$.

\section{Discussion}

In this study, we have shown that cities whose residents are more inclined to walk or cycle in their everyday life are safer for vulnerable road users. Interestingly, the effect of pedestrian modal share extends beyond vulnerable users and such cities also see less deaths or serious injuries among car occupants. Our observation that a high rate of walking and cycling is associated with a smaller number of deaths and serious injuries was already noted by a seminal study of Jacobsen [38. Our results confirm that early finding, and extend it by showing that more walkers and cyclists imply more safety for drivers too. Even though there have been significant efforts in recent years to integrate road safety into urban mobility plans of many cities, the incentives to walk or cycle remain among the most promising routes to make cities safer for pedestrians, cyclists and drivers. A notable example is the city of Oslo, which has successfully reached the Vision Zero milestone of zero vulnerable road deaths in 2019, through a concerted effort to turn roadway decision-making from car-centric to people-centric [39. Another conclusion of our study is the relative impact of low-speed limited roads on vulnerable users. According to our analysis, a larger proportion of speed limited roads is associated with a smaller number of injuries involving car drivers, but there is no clear association with the number of casualties among cyclists and pedestrians.

In the interpretation of the results, it is important to note that our study comes with limitations. We 

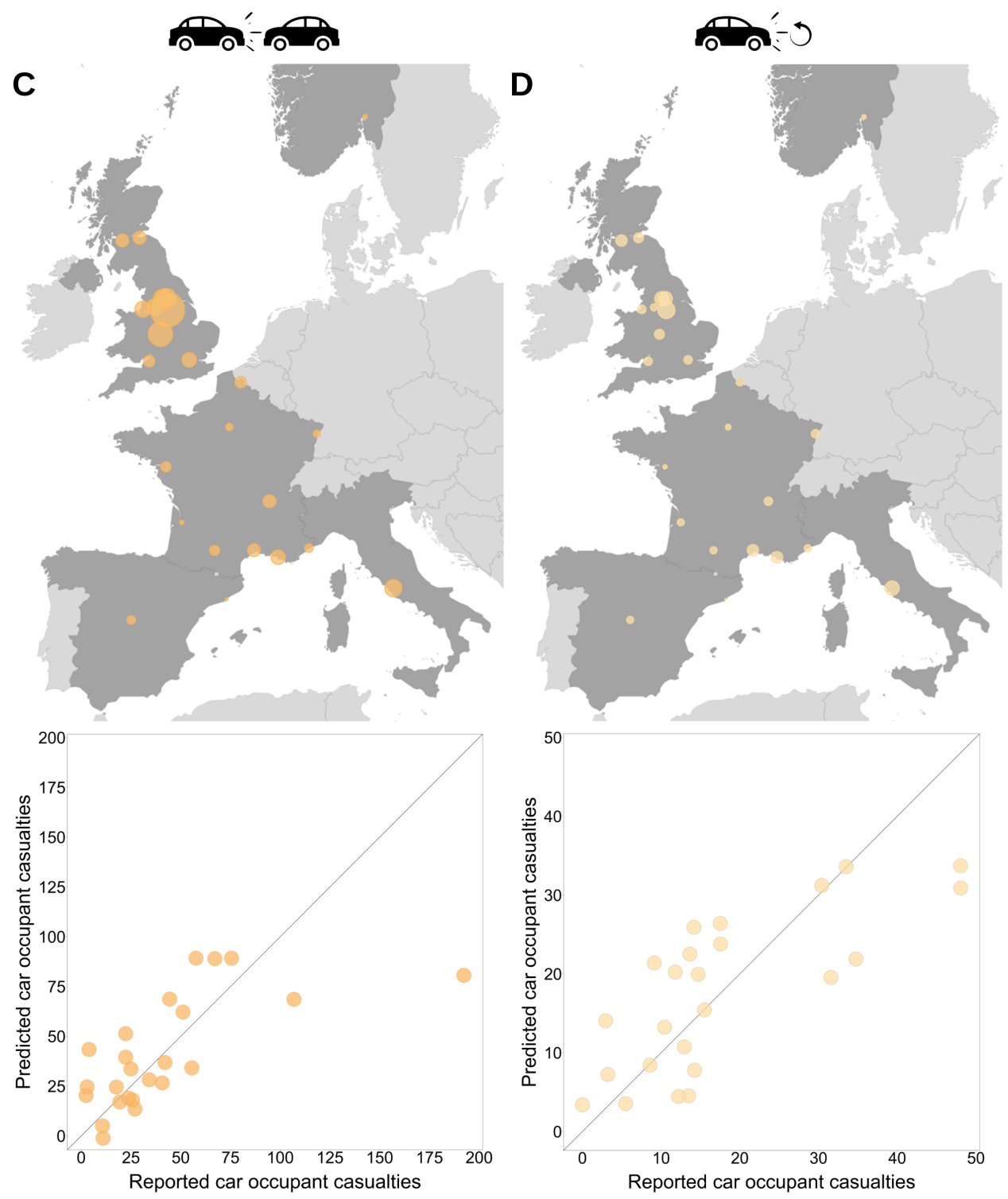

Figure 6: Collisions involving cars: maps of the collisions and performance of the models.. Maps are showing the reported numbers of car/taxi occupants killed or seriously injured in a crash among cars or in a single-vehicle crash, normalized by population. Scatter plots show the corresponding prediction results. Panel C (left) refers to car occupants from a car-car crash, while panel D (right) refers to those from a single-vehicle crash. Colours correspond to those seen in Fig. 3 Sheffield has the highest KSI rates among car occupants, doubling the KSI rates of Birmingham. Prediction results showed adjusted $R^{2}=0.302$ for panel $\mathrm{C}$ and adjusted $R^{2}=0.471$ for panel D.

extracted urban features such as city area, protected cycle paths, and low-speed limited zones, from the volunteered geographic information platform OpenStreetMap using OSMnx [7]. Collecting data in this way, we were only able to access the most up-to-date information in each city but we are missing historical records of the urban features under study, thus limiting the investigation of causal effects between the temporal evolution of infrastructures and road injuries. Nevertheless, these crowdsourced data, which have been shown to be reliable and relatively complete in the Western world [40, 41, allowed us to provide an insightful overview of the relationship between rate of collisions and urban infrastructure. They also have been successfully used in similar urban data science contexts, as in cycling injury analysis [25], in bicycle network analysis [42, 43, 44, or in estimating traffic disruption patterns 45. Apart from novel data sources, also state-of-the-art machine learning methods are currently innovating in road safety research, e.g. with decision trees or neural networks [46, 47, 48, 49.

Another limitation of our study lies in the heterogeneity of the data collection process across countries. We focused on the KSI statistics as their definition is rather uniform in Europe, however, the collection of crash data may not be consistent in all countries and in particular deaths or serious injuries of vulnerable road users may go underreported [50, 12. Several efforts are currently in place to harmonize the collection of KSI numbers in Europe, for instance the maintenance of the CARE database, a community database on road crashes resulting 
in death or injury for Europe [51.

Further, by definition our findings of statistical associations cannot distinguish cause and effect nor identify possible confounding factors that are not part of the data sets, and we were forced to work with a sample size of 24 cities in no more than 5 countries, due to limitations in publicly available road crash data detailed enough for our ecological analysis approach. In particular, our focus on multiple cities and modes implied restriction of the data to a common denominator, thus excluding possible additional exposure data such as driven kilometers as such data are not publicly available for multiple cities and modes.

Finally, we focused on the potential impact of urban features on the injuries of the most vulnerable road users, however the introduction of additional socioeconomic factors into the model, such as per capita income, per capita expenditure on alcohol, or age cohorts [52, 53, could increase its predictive power and better explain the reported KSI rates by user groups in European cities.

In recent years, several European countries have developed national walking and cycling strategies aimed at improving pedestrian and cyclist safety. However, only six European countries have drafted a national walking strategy and among them, only Finland and Luxembourg have defined a target for increasing the walking modal share [50]. Our results suggest that setting concrete targets for increasing modal shares of walking and cycling represents an effective strategy toward more sustainable and safer cities.

\section{Methods}

\section{Data collection}

We used data from various sources shown in Table S1. Data on road crashes were downloaded from the open data portals, with the exception of the data for Oslo, which was provided by the Norwegian Public Roads Administration upon request. Road crash statistics relate to personal injury crashes on public roads that were reported to the police in 2018. Population estimates for the same year were collected from the corresponding National Statistics Office of each country.

Data on urban features were downloaded from OpenStreetMap (OSM), a free, editable map of the world, built by volunteers. We used OSMnx, a Python package for modelling, projecting, visualization, and analysis of real-world street networks from OSM's APIs [7, to collect the following urban features:

- City area in $\mathrm{km}^{2}$. We selected the administrative surface of a city.

- Driving area in $\mathrm{km}$. We selected all the drivable streets by choosing drive as network type.

- Cycling area in $\mathrm{km}$. We selected all the protected cycling paths by choosing bike as network type and by specifying related custom filters.

- Speed limited area in $\mathrm{km}$. We selected all the streets with speed limit of $\leqslant 30 \mathrm{~km} / \mathrm{h}$ or $\leqslant 20 \mathrm{mi} / \mathrm{h}$ by choosing drive as network type and by specifying related custom filters.

Modal share percentages in walking, cycling, public transport and motor vehicles were gathered from the European Platform on Mobility Management (EPOMM), a network of governments in European countries, represented by the Ministries responsible for Mobility Management. They developed The EPOMM Modal Split Tool (TEMS) with comparable modal split data from European cities with more than 100.000 inhabitants.

From the extracted urban features and population data we calculated the first three features, out of seven used for our analysis:

1. City density. Population per $\mathrm{km}^{2}$.

2. Cycling area share. The ratio of cycling area and driving area.

3. Speed limit area share. The ratio of speed limited area and driving area.

4. Walking mode share in percent.

5. Cycling mode share in percent.

6. Public transport mode share in percent.

7. Motor vehicles mode share in percent. 


\section{Casualty matrix}

Raw data on road crashes was cleaned and transformed to show only relevant information used for the casualty matrix calculation. Each row of the cleaned data set corresponds to a unique casualty, while columns contain the following details:

- Crash Index. Unique index for each crash, used to connect vehicles and casualties to the corresponding crash.

- Date.

- Number of Vehicles. Total count of vehicles in a crash.

- Number of Casualties. Total count of casualties in a crash.

- Vehicle Reference. Reference to each vehicle in a crash, used to connect vehicles with the corresponding casualty.

- Vehicle Type. Options: Bicycle, Powered Two-Wheeler (PTW), Car/Taxi, Bus/Coach, Goods Vehicle or Other Vehicles.

- Casualty Reference. Reference to each casualty in a crash, used to connect casualties with the corresponding vehicle.

- Casualty Class. Options: Driver, Passenger, Pedestrian.

- Casualty Type. Options: Pedestrian, Cyclist, PTW occupant, Car/Taxi occupant, Bus/Coach occupant, Goods Vehicle occupant or Other Vehicles occupant.

- Casualty Severity. Options: killed (on spot or died within 30 days of the crash), seriously injured (hospitalized for $>24$ hours) or slightly injured (hospitalized for $\leqslant 24$ hours).

Casualty Type information was available only in the UK data set which made the casualty matrix calculation easier, so we also formed this column in the rest of the data sets based on the Casualty Class and Vehicle Type columns. This enabled us to base our analysis on the number of inter-mode casualties, instead of the common approach focusing on the total number of casualties per each type [36. For example, a pedestrian casualty from a crash between two cars and a pedestrian was counted as a pedestrian injured in a pedestrian-car crash. Similarly, an injured car occupant from a crash with four cars was counted as a car occupant injured in an car-car crash. Regarding the casualty severity levels, casualties with slight injuries were removed from the data set and only killed or seriously injured (KSI) people were observed. We eliminated casualties from crashes with $>2$ different parties involved (including pedestrians), as they represented $\leqslant 2 \%$ of total KSI casualties in each city, which aligns with previous research [46. Also, all the crashes with missing relevant data (mentioned above) were not taken into account.

From the newly created data set, we formed two pivot tables, one with Vehicle Type counts as columns, and another one with Casualty Type counts as columns. This time, each row of both tables corresponded to a unique crash. These two tables were joined into a single table based on Crash Index and we queried them twice for all possible casualty-vehicle pairs - at first for only fatal casualties and then for the seriously injured ones. These counts were used to create the KSI casualty matrix for each city. Rows of the matrix represent casualty types, while columns represent vehicle types. Finally, each matrix cell represents the number of casualties from one casualty-vehicle pair. For the next steps, we observed only the following six casualty-vehicle pairs from the casualty matrix (we chose the pairs with median value $>5$ ):

- pedestrian - car (pedestrians killed or seriously injured in a crash between pedestrians and cars/taxis).

- cyclist - car (cyclists killed or seriously injured in a crash between bicycles and cars/taxis).

- PTW - itself (PTW occupants killed or seriously injured in a single-vehicle crash).

- PTW - car (PTW occupants killed or seriously injured in a crash between PTWs and cars/taxis).

- car - itself (car/taxi occupants killed or seriously injured in a single-vehicle crash).

- car - car (car/taxi occupants killed or seriously injured in a crash between two or more cars/taxis). 


\section{Predicting the number of casualties}

We used multiple linear regression to explain the potential relations between the urban features (7 input variables) and the number of inter-mode casualties (6 target variables), resulting in six linear models. The input variables were standardized by scaling variance to one and centering mean to zero. The target variables were firstly normalized by population (per 1 million inhabitants) and then standardized the same way as the input variables. In order to perform variable selection, we used Lasso regression [54], defined as:

$$
\hat{\beta}_{\text {lasso }}(\alpha)=\operatorname{argmin}_{\beta}\|\mathbf{y}-X \beta\|_{2}^{2}+\alpha\|\beta\|_{1}
$$

where $y$ is the number of inter-mode casualties for the observed pair, $X$ is a matrix of urban features for each city, $\alpha$ is the penalty parameter and $\beta$ is a vector of regression coefficients.

Variables were chosen with the following setup: Lasso as the estimator, $1000 \alpha$ values spaced evenly on a log scale within the interval $\left[10^{-1}, 10^{0}\right], 3$-fold cross-validation and mean squared error as the scoring method. The search found the best estimator (the best $\alpha$ value), which we used to fit the data and identify the important variables. The prediction with selected variables was performed using the ordinary least squares (OLS) model and 3 -fold cross-validation.

The selected variables were used for the final ordinary least squares regression. We performed inverse transformation to scale back the data to the original representation. This pipeline was repeated for all six linear models. Results for four of them (pedestrians injured by a car or taxi, cyclists injured by a car or taxi, car or taxi occupants injured on their own and car or taxi occupants injured by another car or taxi) are discussed in details in section 2

\section{Data availability}

Computed inter-mode road crashes data and urban features for 24 cities, used in this study, are available at: https://github.com/klnmrn/urbanroadsafety. Other data sources are reported in Table S1.

\section{Code availability}

The Python code developed for the data analysis is available at: https://github.com/klnmrn/urbanroadsafety.

\section{Acknowledgments}

We acknowledge the support of the Lagrange Project funded by the CRT Foundation. We thank Monica Knoblauch Brathaug from the Norwegian Public Roads Administration for the data provided. We also thank Geoff Boeing for helpful comments concerning OSMnx. Transportation icons designed by Freepik.

\section{Author contributions}

M.K. acquired and processed the data. All authors contributed to the conception and design of the work, analysis and interpretation of the data, and drafted the work.

\section{References}

[1] Global status report on road safety 2018. World Health Organization, 2018.

[2] United Nations General Assembly. Transforming our world: The 2030 agenda for sustainable development. a/res/70/1. Technical report, United Nations General Assembly, 2015.

[3] European Commission. EU road safety policy framework 2021-2030 - next steps towards "vision zero". Technical report, European Commission, 2019.

[4] M Khayesi. Vulnerable road users or vulnerable transport planning? front. sustain. Cities, 2:25, 2020.

[5] Jacqueline M Klopp and Danielle L Petretta. The urban sustainable development goal: Indicators, complexity and the politics of measuring cities. Cities, 63:92-97, 2017.

[6] Roni Utriainen, Markus Pöllänen, and Heikki Liimatainen. Road safety comparisons with international data on seriously injured. Transport Policy, 66:138-145, 2018. 
[7] Geoff Boeing. OSMnx: New methods for acquiring, constructing, analyzing, and visualizing complex street networks. Computers, Environment and Urban Systems, 65:126-139, 2017.

[8] Bernd Resch and Michael Szell. Human-centric data science for urban studies. ISPRS International Journal of Geo-Information, 8(584), 2019.

[9] Darren Walton, Dan Jenkins, Roselle Thoreau, Simon Kingham, and Michael Keall. Why is the rate of annual road fatalities increasing? A unit record analysis of New Zealand data (2010-2017). Journal of Safety Research, 72:67-74, 2020.

[10] Víctor Cantill, Luis Márquez, and Carmelo J. Díaz. An exploratory analysis of factors associated with traffic crashes severity in Cartagena, Colombia. Accident Analysis \& Prevention, 146, 2020.

[11] Grigorios Fountas, Achille Fonzone, Niaz Gharavi, and Tom Ryez. The joint effect of weather and lighting conditions on injury severities of single-vehicle accidents. Analytic Methods in Accident Research, 27, 2020.

[12] Piotr Olszewski, Piotr Szagala, Daniel Rabczenko, and Anna Zielińska. Investigating safety of vulnerable road users in selected EU countries. Journal of Safety Research, 68:49-57, 2019.

[13] Michael Branion-Calles, Thomas Götschi, Trisalyn Nelson, Esther Anaya-Boig, Ione Avila-Palencia, Alberto Castro, Tom Cole-Hunter, Audrey de Nazelle, Evi Dons, Mailin Gaupp-Berghausen, Regine Gerike, Luc Int Panis, Sonja Kahlmeier, Mark Nieuwenhuijsen, David Rojas-Rueda, and Meghan Winters. Cyclist crash rates and risk factors in a prospective cohort in seven European cities. Accident Analysis and Prevention, 141, 2020.

[14] Wouter Van den Berghe, Michael Schachner, Veronica Sgarra, and Nicola Christie. The association between national culture, road safety performance and support for policy measures. IATSS Research, 44:197-211, 2020.

[15] Hamid Safarpour, Davoud Khorasani-Zavareh, and Reza Mohammadi. The common road safety approaches: A scoping review and thematic analysis. Chinese Journal of Traumatology, 23:113-121, 2020.

[16] Dinesh Mohan, Geetam Tiwari, Mathew Varghese, Kavi Bhalla, Denny John, Ashrita Saran, and Howard White. PROTOCOL: Effectiveness of road safety interventions: An evidence and gap map. Campbell Systematic Reviews, 16, 2020.

[17] Faan Chen, Jingyang Lyu, and Tianye Wang. Benchmarking road safety development across OECD countries: An empirical analysis for a decade. Accident Analysis and Prevention, 147, 2020.

[18] Stéphanie Blaizot, Francis Papon, Mohamed Mouloud Haddak, and Emmanuelle Amoros. Injury incidence rates of cyclists compared to pedestrians, car occupants and powered two-wheeler riders, using a medical registry and mobility data, Rhône County, France. Accident Analysis and Prevention, 58:35-45, 2013.

[19] Ghazal Batouli, Manze Guo, Bruce Janson, and Wesley Marshall. Analysis of pedestrian-vehicle crash injury severity factors in Colorado 2006-2016. Accident Analysis and Prevention, 148, 2020.

[20] George Yannis, Dimitrios Nikolaou, Alexandra Laiou, Yvonne Achermann Stürmer, Ilona Buttler, and Dagmara Jankowska-Karpa. Vulnerable road users: Cross-cultural perspectives on performance and attitudes. IATSS Research, 44:220-229, 2020.

[21] A. Värnild, P. Tillgren, and P. Larm. What types of injuries did seriously injured pedestrians and cyclists receive in a Swedish urban region in the time period 2003-2017 when Vision Zero was implemented? Public Health, 181:59-64, 2020.

[22] Lynn B. Meuleners, Michelle Fraser, Marilyn Johnson, Mark Stevenson, Geoffrey Rose, and Jennie Oxley. Characteristics of the road infrastructure and injurious cyclist crashes resulting in a hospitalisation. Accident Analysis and Prevention, 136, 2020.

[23] Mariana Vilaca, Nélia Silva, and Margarida C. Coelho. Statistical Analysis of the Occurrence and Severity of Crashes Involving Vulnerable Road Users. Transportation Research Procedia, 20:1113-1120, 2017.

[24] Marco Te Brömmelstroet. Framing systemic traffic violence: media coverage of dutch traffic crashes. Transportation research interdisciplinary perspectives, 5:100109, 2020.

[25] Rachel Aldred, Anna Goodman, John Gulliver, and James Woodcock. Cycling injury risk in London: A case-control study exploring the impact of cycle volumes, motor vehicle volumes, and road characteristics including speed limits. Accident Analysis \& Prevention, 117:75-84, 2018. 
[26] Rachel Aldred, Susana García-Herrero, Esther Anaya, Sixto Herrera, and Miguel Ángel Mariscal. Cyclist injury severity in Spain: a Bayesian analysis of police road injury data focusing on involved vehicles and route environment. International journal of Environmental Research and Public Health, 17(1):96, 2020.

[27] Rul von Stülpnagel and Jonas Lucas. Crash risk and subjective risk perception during urban cycling: Evidence for congruent and incongruent sources. Accident Analysis and Prevention, 142, 2020.

[28] Hongliang Ding, N.N. Sze, Haojie Li, and Yanyong Guo. Roles of infrastructure and land use in bicycle crash exposure and frequency: T A case study using Greater London bike sharing data. Accident Analysis and Prevention, 144, 2020.

[29] Jaimy Fischer, Trisalyn Nelson, Karen Laberee, and Meghan Winters. What does crowdsourced data tell us about bicycling injury? A case study in a mid-sized Canadian city. Accident Analysis and Prevention, $145,2020$.

[30] Germán A. Carvajal, Olga L. Sarmiento, Andrés L. Medaglia, Sergio Cabrales, Daniel A. Rodríguez, D. Alex Quistberg, and Segundo López. Bicycle safety in Bogotá: A seven-year analysis of bicyclists' collisions and fatalities. Accident Analysis and Prevention, 144, 2020.

[31] Rebecca Ling, Linda Rothman, Marie-Soleil Cloutier, Colin Macarthur, and Andrew Howard. Cyclistmotor vehicle collisions before and after implementation of cycle tracks in Toronto, Canada. Accident Analysis and Prevention, 135, 2020.

[32] Sareh Bahrololoom, William Young, and David Logan. Modelling injury severity of bicyclists in bicycle-car crashes at intersections. Accident Analysis and Prevention, 144, 2020.

[33] Wesley E. Marshall and Nicholas N. Ferenchak. Why cities with high bicycling rates are safer for all road users. Journal of Transport \& Health, 13:285-301, 2019.

[34] Felipe E. Pedroso MD MPH, Federico Angriman MD MPH, Alexandra L. Bellows BS, and Kathryn Taylor PhD. Bicycle Use and Cyclist Safety Following Boston's Bicycle Infrastructure Expansion, 2009-2012. Am J Public Health, 106:2171-2177, 2016.

[35] Jessica B. Cicchino, Melissa L. McCarthy, Craig D. Newgard, Stephen P. Wall, Charles J. Di Maggio, Paige E. Kulie, Brittany N. Arnold, and David S. Zuby. Not all protected bike lanes are the same: Infrastructure and risk of cyclist collisions and falls leading to emergency department visits in three U.S. cities. Accident Analysis and Prevention, 141, 2020.

[36] A Santacreu. Cycling Safety: Summary and Conclusions of the ITF Roundtable on Cycling Safety, 29-30 January 2018, Paris. 2018.

[37] ITF. Road Safety in European Cities: Performance Indicators and Governance Solutions. Technical report, International Transport Forum Policy Papers, No. 67, OECD Publishing, Paris, 2019.

[38] Peter L Jacobsen. Safety in numbers: more walkers and bicyclists, safer walking and bicycling. Injury prevention, 9(3):205-209, 2003.

[39] Anders Hartmann and Sarah Abel. How Oslo achieved zero. ite journal, pages 32-38, 2020.

[40] Mordechai Haklay. How good is volunteered geographical information? A comparative study of OpenStreetMap and Ordnance Survey datasets. Environment and planning B: Planning and design, 37(4):682$703,2010$.

[41] Christopher Barrington-Leigh and Adam Millard-Ball. The world's user-generated road map is more than 80\% complete. PloS one, 12(8):e0180698, 2017.

[42] Luis E. Olmos, Maria Sol Tadeo, Dimitris Vlachogiannis, Fahad Alhasoun, Xavier Espinet Alegre, Catalina Ochoa, Felipe Targa, and Marta C. González. A data science framework for planning the growth of bicycle infrastructures. Transportation Research Part C, 115, 2020.

[43] Luis Guillermo Natera Orozco, Federico Battiston, Gerardo Iñiguez, and Michael Szell. Extracting the multimodal fingerprint of urban transportation networks. Transport Findings, 13171, 2020.

[44] Luis Guillermo Natera Orozco, Federico Battiston, Gerardo Iñiguez, and Michael Szell. Data-driven strategies for optimal bicycle network growth. Royal Society Open Science, 7(201130), 2020.

[45] Chico Q Camargo, Jonathan Bright, Graham McNeill, Sridhar Raman, and Scott A Hale. Estimating traffic disruption patterns with volunteered geographic information. Scientific reports, 10(1):1-8, 2020. 
[46] Gabriele Prati, Luca Pietrantoni, and Federico Fraboni. Using data mining techniques to predict the severity of bicycle crashes. Accident Analysis and Prevention, 101:44-54, 2017.

[47] Alfonso Montella, Rocìo de Oña, Filomena Mauriello, Maria Rella Riccardi, and Giuseppe Silvestro. A data mining approach to investigate patterns of powered two-wheeler crashes in Spain. Accident Analysis and Prevention, 134, 2020.

[48] Le Yu, Bowen Du, Xiao Hu, Leilei Sun, Liangzhe Han, and Weifeng Lv. Deep spatio-temporal graph convolutional network for traffic accident prediction. Neurocomputing, 423:135-147, 2021.

[49] Jeremiah Roland, Peter D. Way, Connor Firat, Thanh-Nam Doan, and Mina Sartipi. Modeling and predicting vehicle accident occurrence in Chattanooga, Tennessee. Accident Analysis and Prevention, 149, 2021.

[50] Dovilé Adminaité-Fodor and Graziella Jost. How safe is walking and cycling in Europe? PIN Flash Report 38, European Transport Safety Council, January 2020.

[51] Robert Bauer, Klaus Machata, Christian Brandstaetter, George Yannis, Alexandra Laiou, and Katerina Folla. Road traffic accidents in european urban areas. In Proceedings of the 1st European Road Infrastructure Congress, Leeds, UK, pages 18-20, 2016.

[52] Robert B Noland and Mohammed A Quddus. Analysis of pedestrian and bicycle casualties with regional panel data. Transportation research record, 1897(1):28-33, 2004.

[53] Paraskevas Nikolaou, Katerina Folla, Loukas Dimitriou, and George Yannis. European countries' road safety evaluation by taking into account multiple classes of fatalities. Transportation research procedia, $52: 284-291,2021$.

[54] Robert Tibshirani. Regression Shrinkage and Selection via the Lasso. Journal of the Royal Statistical Society: Series B (Methodological), 58(1):267-288, 1996. 


\section{Supplementary Information}

This is the supplementary information for the manuscript Identifying urban features for vulnerable road user safety in Europe by Marina Klanjčić, Laetitia Gauvin, Michele Tizzoni, and Michael Szell, containing a supplementary table and figures. 
Table S1: List of sources of collision data.

\begin{tabular}{|c|c|c|}
\hline City & Source & Ref. \\
\hline Barcelona & Barcelona City Hall & $\begin{array}{l}\text { https://opendata- } \\
\text { ajuntament.barcelona.cat/data/ } \\
\text { en/dataset?q=accidents\&sort= } \\
\text { fecha_publicacion+desc }\end{array}$ \\
\hline Madrid & City Council of Madrid & $\begin{array}{l}\text { https://datos.madrid.es/ } \\
\text { sites/v/index.jsp?vgnextoid= } \\
\text { 7c2843010d9c3610VgnVCM2000001f4a900aRCRD\& } \\
\text { vgnextchannel= } \\
\text { 374512b9ace9f310VgnVCM100000171f5a0aRCRD }\end{array}$ \\
\hline Oslo & Norwegian Public Roads Administration & Received upon request. \\
\hline Rome & Municipality of Rome & $\begin{array}{l}\text { https://dati.comune.roma.it/catalog/ } \\
\text { dataset/d655 }\end{array}$ \\
\hline Cities in France & Ministry of Interior & $\begin{array}{l}\text { https://www.data.gouv.fr/fr/datasets/ } \\
\text { bases-de-donnees-annuelles-des- } \\
\text { accidents-corporels-de-la-circulation- } \\
\text { routiere-annees-de-2005-a-2019/ }\end{array}$ \\
\hline Cities in the United Kingdom & Department for Transport & $\begin{array}{l}\text { https://data.gov.uk/dataset/cb7ae6f0- } \\
\text { 4be6-4935-9277-47e5ce24a11f/road- } \\
\text { safety-data }\end{array}$ \\
\hline
\end{tabular}




\begin{tabular}{|c|c|c|c|c|c|c|c|c|c|c|c|c|c|c|c|c|c|c|c|c|c|c|c|c|c|c|c|c|c|}
\hline \multirow[b]{2}{*}{$\dot{\lambda}$} & \multicolumn{7}{|c|}{ Barcelona [ES] } & \multicolumn{7}{|c|}{ Birmingham [GB] } & \multicolumn{7}{|c|}{ Bordeaux [FR] } & \multicolumn{7}{|c|}{ Bradford [GB] } & \\
\hline & 0 & 2 & 16 & 22 & 8 & 10 & 1 & 0 & 2 & 3 & 153 & 5 & 9 & 0 & 0 & 0 & 0 & 13 & 1 & 1 & 2 & 0 & 0 & 2 & 60 & 3 & 7 & 0 & \\
\hline 施 & 1 & 1 & 3 & 5 & 0 & 2 & 1 & 0 & 0 & 0 & 54 & 0 & 2 & 1 & 1 & 0 & 0 & 5 & 0 & 1 & 0 & 8 & 0 & 0 & 14 & 0 & 1 & 0 & \\
\hline$i$ & 29 & 1 & 7 & 96 & 2 & 19 & 2 & 6 & 0 & 0 & 55 & 0 & 9 & 0 & 2 & 1 & 1 & 14 & 0 & 0 & 0 & 8 & 0 & 0 & 11 & 0 & 2 & 0 & \\
\hline م. & 0 & 0 & 0 & 4 & 0 & 4 & 0 & 20 & 0 & 0 & 122 & 0 & 13 & 0 & 3 & 0 & 0 & 1 & 0 & 1 & 0 & 18 & 0 & 0 & 31 & 1 & 5 & 0 & \\
\hline 回 & 6 & 0 & 0 & 1 & 0 & 0 & 0 & 0 & 0 & 0 & 1 & 0 & 0 & 0 & 0 & 0 & 0 & 0 & 0 & 0 & 0 & 1 & 0 & 0 & 0 & 0 & 0 & 0 & \\
\hline 昷 & 0 & 0 & 0 & 2 & 0 & 0 & 0 & 0 & 0 & 0 & 2 & 0 & 0 & 0 & 0 & 0 & 0 & 0 & 0 & 0 & 0 & 2 & 0 & 0 & 1 & 0 & 0 & 0 & \\
\hline OTHER & 0 & 0 & 0 & 2 & 1 & 0 & 0 & 1 & 0 & 0 & 0 & 0 & 0 & 0 & 0 & 0 & 0 & 1 & 0 & 0 & 0 & 2 & 0 & 0 & 2 & 0 & 0 & 0 & \\
\hline & \multicolumn{7}{|c|}{ Bristol [GB] } & \multicolumn{7}{|c|}{ Edinburgh [GB] } & \multicolumn{7}{|c|}{ Glasgow [GB] } & \multicolumn{7}{|c|}{ Inner London [GB] } & \\
\hline$\dot{\lambda}$ & 0 & 1 & 1 & 25 & 2 & 0 & 0 & 0 & 1 & 2 & 33 & 8 & 1 & 2 & 0 & 0 & 4 & 61 & 6 & 8 & 0 & 0 & 54 & 129 & 398 & 60 & 77 & 12 & \\
\hline s. & 0 & 0 & 1 & 28 & 0 & 4 & 0 & 3 & 1 & 0 & 15 & 3 & 3 & 0 & 1 & 0 & 0 & 23 & 0 & 3 & 0 & 48 & 19 & 18 & 340 & 12 & 76 & 9 & \\
\hline in & 1 & 0 & 0 & 22 & 0 & 1 & 0 & 1 & 0 & 0 & 17 & 0 & 1 & 0 & 2 & 0 & 0 & 16 & 0 & 1 & 0 & 72 & 5 & 15 & 371 & 6 & 50 & 3 & \\
\hline مים & 6 & 0 & 0 & 11 & 0 & 4 & 1 & 7 & 0 & 0 & 14 & 0 & 1 & 0 & 11 & 0 & 0 & 14 & 0 & 4 & 0 & 44 & 0 & 1 & 123 & 5 & 18 & 3 & \\
\hline 回 & 0 & 0 & 0 & 0 & 0 & 0 & 0 & 7 & 0 & 0 & 2 & 0 & 0 & 0 & 8 & 0 & 0 & 2 & 0 & 0 & 0 & 53 & 0 & 2 & 8 & 0 & 0 & 0 & \\
\hline 直 & 0 & 0 & 0 & 0 & 0 & 0 & 0 & 0 & 0 & 0 & 0 & 0 & 0 & 0 & 0 & 0 & 0 & 1 & 0 & 0 & 0 & 6 & 0 & 1 & 3 & 1 & 2 & 1 & \\
\hline OTHER & 0 & 0 & 0 & 0 & 0 & 0 & 0 & 0 & 0 & 0 & 0 & 0 & 0 & 0 & 0 & 0 & 0 & 3 & 0 & 0 & 0 & 2 & 0 & 0 & 4 & 1 & 0 & 0 & 400 \\
\hline \multicolumn{8}{|c|}{ Leeds [GB] } & & & & lle [FF & & & & & & Liver & pool & [GB] & & & & & & on $[\mathrm{Fr}$ & & & & \\
\hline 卒 & 0 & 1 & 0 & 75 & 6 & 6 & 0 & 0 & 0 & 0 & 5 & 0 & 0 & 1 & 0 & 3 & 1 & 71 & 1 & 8 & 0 & 0 & 2 & 5 & 31 & 4 & 1 & 2 & -350 \\
\hline क्षा & 0 & 0 & 1 & 50 & 2 & 7 & 0 & 0 & 0 & 1 & 1 & 0 & 0 & 0 & 1 & 0 & 0 & 27 & 1 & 2 & 0 & 2 & 1 & 2 & 11 & 0 & 1 & 0 & 350 \\
\hline$i$ & 17 & 0 & 0 & 43 & 1 & 6 & 0 & 2 & 0 & 0 & 7 & 0 & 0 & 1 & 5 & 0 & 0 & 22 & 0 & 2 & 0 & 12 & 0 & 1 & 39 & 0 & 2 & 1 & \\
\hline هـ & 24 & 2 & 0 & 53 & 2 & 19 & 1 & 2 & 0 & 0 & 6 & 0 & 0 & 0 & 7 & 0 & 0 & 22 & 0 & 3 & 0 & 8 & 0 & 0 & 21 & 0 & 1 & 2 & -300 \\
\hline 且 & 3 & 0 & 0 & 3 & 0 & 0 & 0 & 0 & 0 & 0 & 0 & 0 & 0 & 0 & 1 & 0 & 0 & 0 & 0 & 0 & 0 & 0 & 0 & 0 & 1 & 0 & 0 & 0 & \\
\hline 且 & 1 & 0 & 0 & 3 & 0 & 2 & 0 & 0 & 0 & 0 & 0 & 0 & 0 & 0 & 1 & 0 & 0 & 0 & 0 & 0 & 0 & 0 & 0 & 0 & 0 & 0 & 0 & 0 & \\
\hline OTHER & 0 & 0 & 0 & 0 & 0 & 1 & 0 & 0 & 0 & 0 & 0 & 0 & 0 & 0 & 0 & 0 & 0 & 0 & 0 & 0 & 0 & 1 & 0 & 0 & 4 & 0 & 0 & 1 & -250 \\
\hline & & & & drid $[E$ & & & & & & lancl & nester & [GB] & & & & & Mars & seille & [FR] & & & & & Montp & oellier & {$[\mathrm{FR}]$} & & & \\
\hline$\hat{x}$ & 0 & 2 & 23 & 201 & 16 & 25 & 7 & 0 & 1 & 2 & 40 & 5 & 4 & 0 & 0 & 0 & 25 & 56 & 2 & 3 & 2 & 0 & 0 & 3 & 21 & 1 & 0 & 0 & \\
\hline 40 & 26 & 6 & 3 & 18 & 0 & 5 & 1 & 0 & 0 & 1 & 34 & 0 & 5 & 0 & 0 & 0 & 2 & 9 & 1 & 2 & 0 & 0 & 0 & 0 & 4 & 0 & 0 & 0 & \\
\hline$\dot{a}$ & 95 & 0 & 5 & 275 & 7 & 23 & 5 & 4 & 0 & 2 & 31 & 2 & 5 & 0 & 45 & 1 & 10 & 146 & 1 & 5 & 2 & 8 & 0 & 0 & 21 & 0 & 0 & 0 & \\
\hline م- & 44 & 0 & 1 & 72 & 0 & 13 & 0 & 5 & 2 & 1 & 28 & 0 & 2 & 1 & 30 & 0 & 0 & 48 & 0 & 2 & 0 & 9 & 0 & 0 & 12 & 0 & 0 & 1 & 150 \\
\hline 回 & 4 & 0 & 1 & 2 & 0 & 1 & 0 & 2 & 0 & 0 & 0 & 1 & 0 & 0 & 0 & 0 & 1 & 0 & 0 & 0 & 1 & 0 & 0 & 0 & 0 & 0 & 0 & 0 & \\
\hline 昷 & 5 & 0 & 1 & 5 & 0 & 1 & 0 & 0 & 0 & 0 & 2 & 0 & 0 & 0 & 1 & 0 & 0 & 1 & 0 & 0 & 0 & 0 & 0 & 0 & 0 & 0 & 0 & 0 & \\
\hline OTHER & 0 & 0 & 0 & 4 & 0 & 1 & 0 & 1 & 0 & 0 & 0 & 0 & 0 & 0 & 0 & 0 & 0 & 3 & 1 & 0 & 0 & 0 & 0 & 0 & 1 & 0 & 0 & 0 & -100 \\
\hline & & & & tes [F & & & & & & & ce [Fr & & & & & & & Io [NC & & & & & & & ris $[\mathrm{F}$ & & & & \\
\hline$\dot{\hat{\lambda}}$ & 0 & 1 & 2 & 13 & 0 & 0 & 3 & 0 & 2 & 6 & 20 & 0 & 3 & 2 & 0 & 2 & 0 & 9 & 2 & 2 & 0 & 0 & 5 & 25 & 58 & 2 & 3 & 4 & \\
\hline 部 & 1 & 1 & 1 & 7 & 1 & 1 & 0 & 0 & 1 & 1 & 2 & 0 & 1 & 0 & 3 & 2 & 0 & 6 & 0 & 2 & 1 & 6 & 1 & 3 & 14 & 1 & 5 & 3 & -50 \\
\hline in & 6 & 0 & 0 & 13 & 0 & 0 & 0 & 6 & 0 & 6 & 50 & 1 & 1 & 1 & 2 & 0 & 0 & 2 & 0 & 1 & 0 & 48 & 0 & 7 & 132 & 0 & 3 & 1 & \\
\hline م- & 1 & 0 & 0 & 6 & 0 & 1 & 1 & 5 & 0 & 2 & 6 & 1 & 0 & 1 & 2 & 0 & 0 & 2 & 0 & 1 & 2 & 12 & 0 & 1 & 24 & 0 & 1 & 1 & \\
\hline 回 & 0 & 0 & 0 & 0 & 0 & 0 & 0 & 0 & 0 & 0 & 0 & 0 & 0 & 0 & 0 & 0 & 0 & 1 & 0 & 0 & 0 & 0 & 0 & 0 & 0 & 0 & 0 & 0 & -0 \\
\hline 且 & 0 & 0 & 0 & 0 & 0 & 0 & 0 & 0 & 0 & 0 & 0 & 0 & 0 & 0 & 2 & 0 & 0 & 0 & 0 & 0 & 0 & 1 & 0 & 0 & 0 & 0 & 0 & 0 & \\
\hline OTHER & 0 & 0 & 0 & 0 & 0 & 0 & 0 & 0 & 0 & 0 & 0 & 0 & 0 & 0 & 2 & 0 & 0 & 0 & 0 & 0 & 0 & 1 & 1 & 0 & 4 & 1 & 0 & 0 & \\
\hline & & & & me [l] & & & & & & Shef & field [ & GB] & & & & & tras & bourg & [FR] & & & & & Toulc & ouse & [FR] & & & \\
\hline$\dot{\boldsymbol{k}}$ & 0 & 1 & 68 & 249 & 8 & 17 & 3 & 0 & 0 & 2 & 66 & 3 & 7 & 1 & 0 & 1 & 0 & 5 & 0 & 0 & 0 & 0 & 0 & 1 & 12 & 1 & 1 & 1 & \\
\hline 施 & 3 & 0 & 1 & 15 & 1 & 2 & 2 & 1 & 0 & 1 & 39 & 1 & 7 & 0 & 0 & 0 & 0 & 8 & 0 & 1 & 0 & 0 & 1 & 0 & 2 & 0 & 1 & 0 & \\
\hline in & 143 & 0 & 10 & 346 & 8 & 34 & 8 & 4 & 0 & 0 & 30 & 0 & 4 & 1 & 4 & 0 & 0 & 8 & 0 & 0 & 1 & 5 & 4 & 0 & 29 & 0 & 1 & 0 & \\
\hline م- & 138 & 0 & 10 & 217 & 11 & 28 & 2 & 28 & 0 & 1 & 112 & 0 & 18 & 0 & 4 & 0 & 0 & 3 & 0 & 0 & 2 & 5 & 0 & 0 & 12 & 0 & 1 & 2 & \\
\hline 昌 & 3 & 0 & 0 & 2 & 0 & 0 & 0 & 4 & 0 & 0 & 4 & 0 & 2 & 0 & 0 & 0 & 0 & 0 & 0 & 0 & 0 & 0 & 0 & 0 & 0 & 0 & 0 & 0 & \\
\hline 直 & 10 & 0 & 0 & 4 & 0 & 1 & 0 & 1 & 0 & 0 & 2 & 0 & 1 & 0 & 0 & 0 & 0 & 0 & 0 & 0 & 0 & 0 & 0 & 0 & 0 & 0 & 0 & 0 & \\
\hline OTHER & 2 & 0 & 0 & 0 & 0 & 0 & 0 & 0 & 0 & 0 & 0 & 0 & 0 & 0 & 0 & 0 & 1 & 0 & 0 & 0 & 0 & 0 & 0 & 0 & 0 & 0 & 0 & 0 & \\
\hline
\end{tabular}

Figure S1: Casualty matrices of all cities and all transport modes 

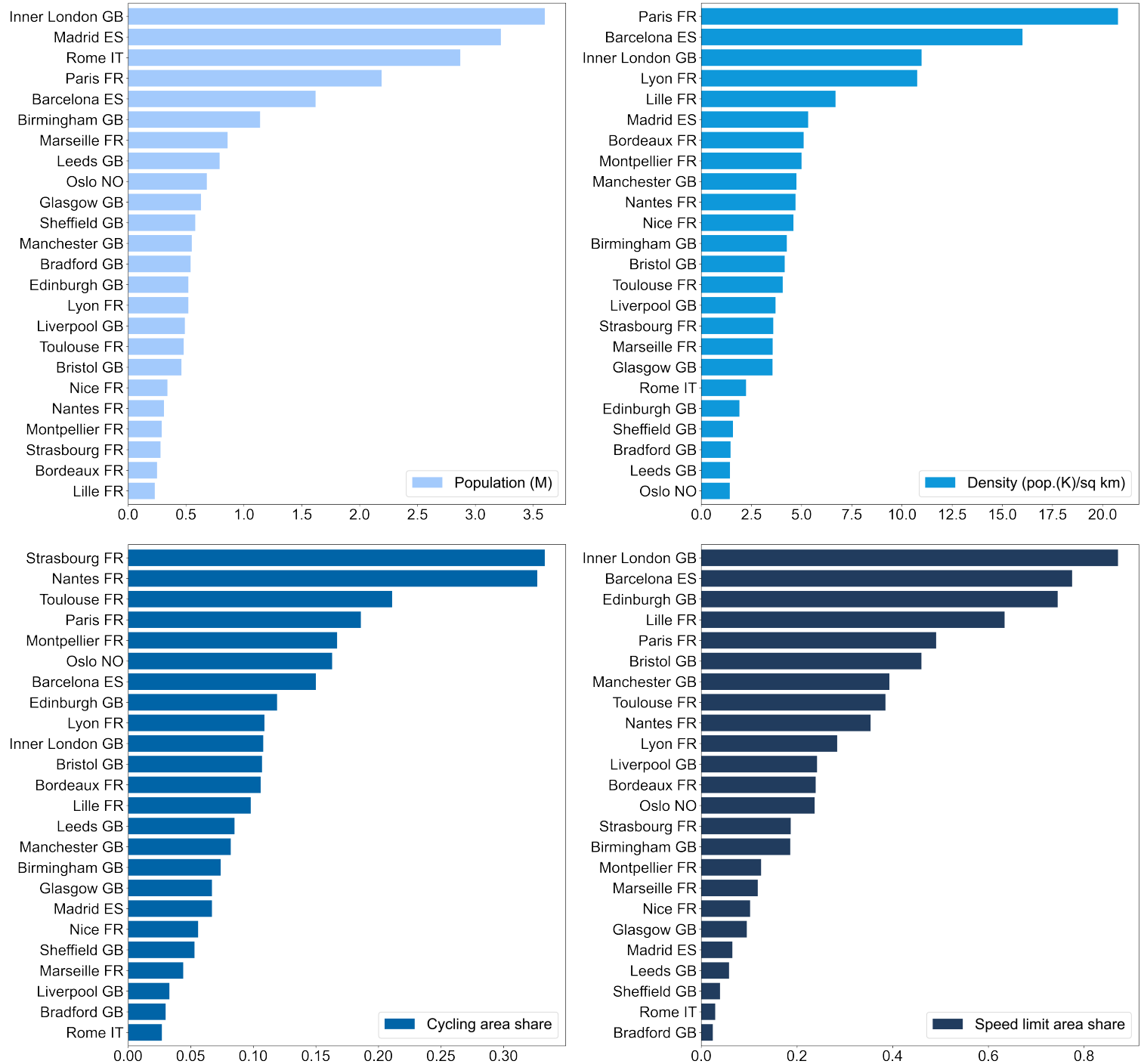

Figure S2: Urban features across cities 

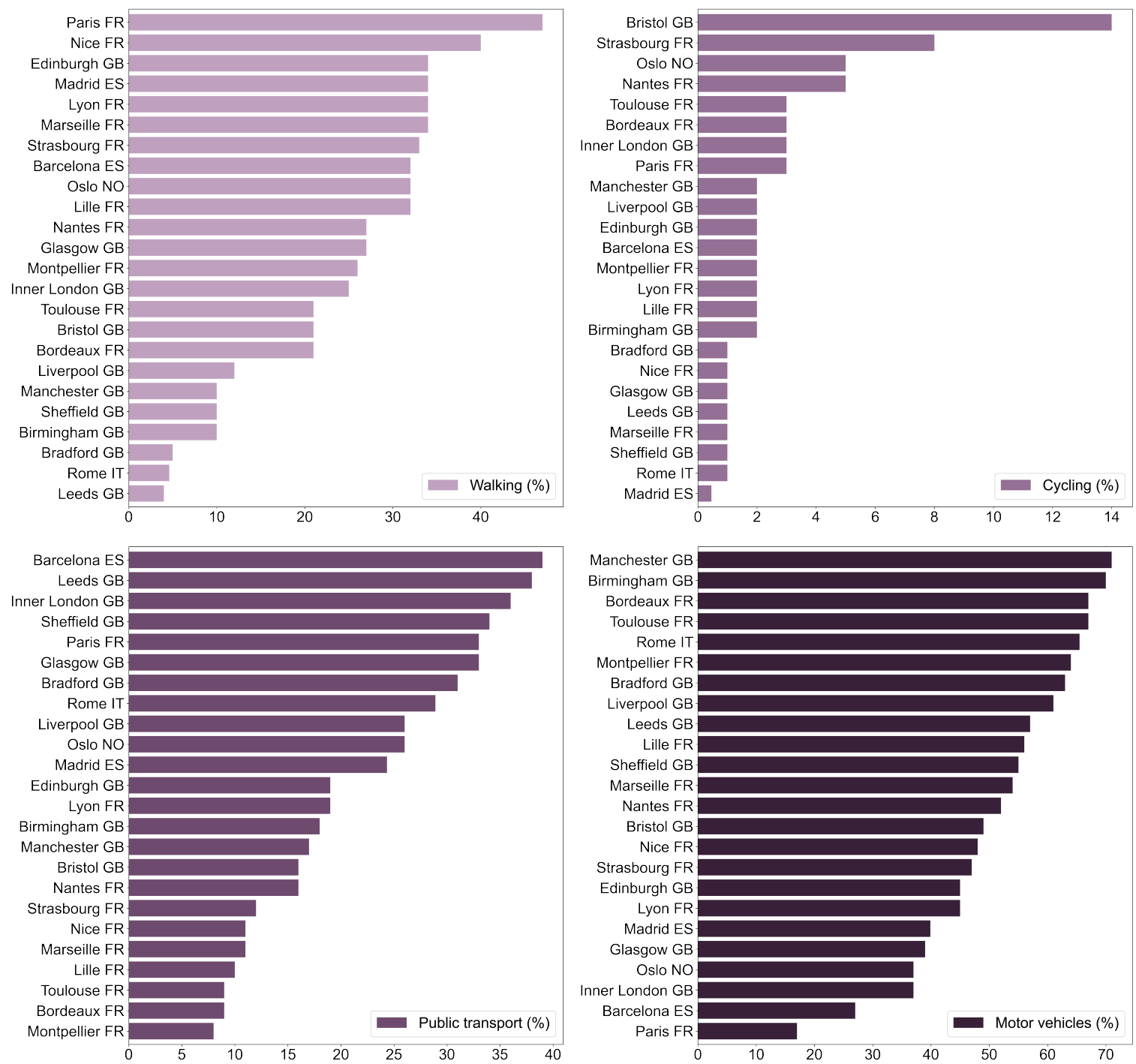

Figure S3: Modal shares across cities 

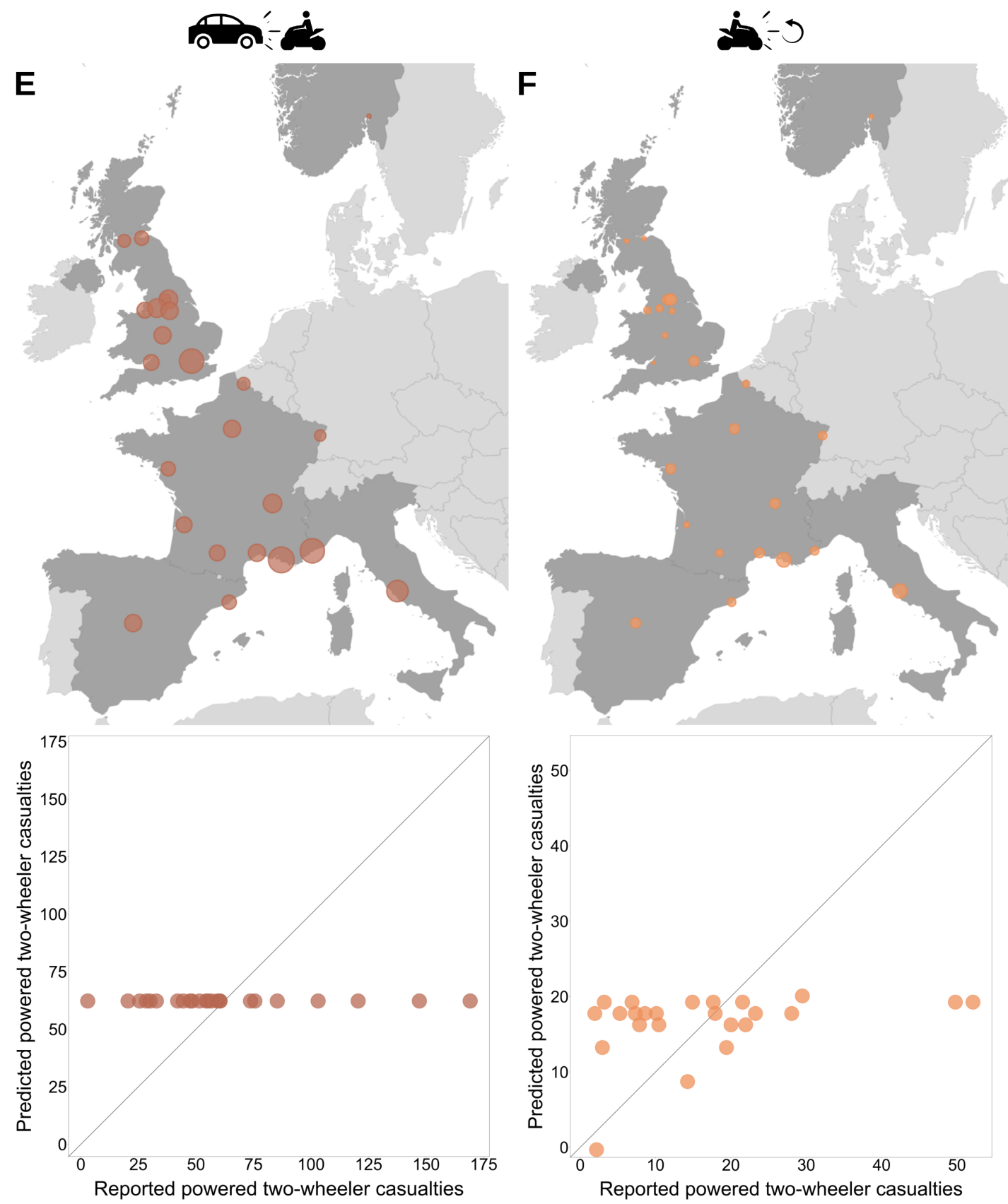

Figure S4: Urban features do not account for the road safety of powered two-wheelers. Maps are showing the reported numbers of powered two-wheeler occupants killed or seriously injured in a road crash, normalized by population. Scatter plots show the corresponding prediction results. Panel E (left) refers to PTW occupants hit by a car, panel F (right) refers to PTW occupants from single-vehicle PTW crashes. Marseille, Rome and Nice have the highest KSI rates among PTW occupants. Lasso regression for the panel E did not select any variables, so the prediction results showed adjusted $R^{2}=0$, while for the panel $\mathrm{F}$, results showed adjusted $R^{2}=0.067$. 